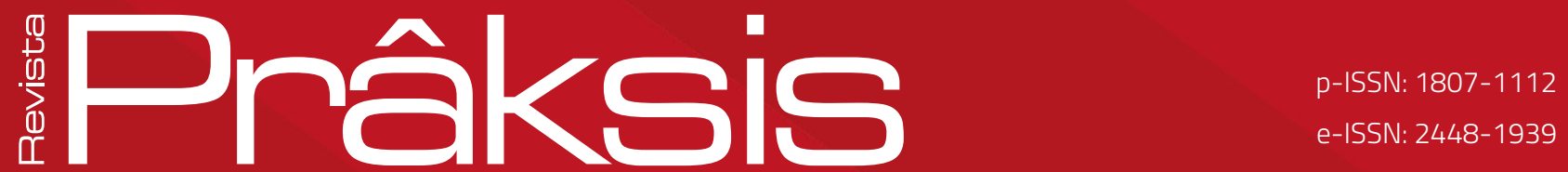

Recebido em: 18 de novembro de 2018 Aprovado em: 20 de janeiro de 2019 Sistema de Avaliação: Double Blind Review RPR |a. 16|n. 2 |p. 81-106| mai./ago. 2019 DOI: https://doi.org/10.25112/rpr.v2i0.1816

\title{
TRANSUERSALIDADE DE GÊNERO EM POLÍTICAS PÚBLICAS: UMA REVISÃO DE LITERATURA
}

\section{GENDER MAINSTREAMING IN PUBLIC POLICIES: A LITERATURE REVIEW}

\section{Sandra Dos Santos Andrade}

Doutora em Educação pela Universidade Federal do Rio Grande do Sul (Porto Alegre/Brasil). Professora na Universidade Federal do Rio Grande do Sul (Porto Alegre/Brasil).

E-mail: sandrasantosandrade@gmail.com.

\section{Dagmar Elisabeth Estermann Meyer}

Doutora em Educação pela Universidade Federal do Rio Grande do Sul (Porto Alegre/Brasil). Professora na Universidade Federal do Rio Grande do Sul (Porto Alegre/Brasil).

E-mail: dagmaremeyer@gmail.com.

\section{Carlos Eduardo Barzotto}

Mestrando em Educação na Universidade Federal do Rio Grande do Sul (Porto Alegre/Brasil) Professor na Rede Municipal de Ensino (Guaíba/Brasil).

E-mail: cebarzotto@gmail.com. 


\section{RESUMO}

Esse artigo se desdobra em pesquisa interinstitucional e multifocal e problematizou alguns dos modos pelos quais o conceito de transversalidade de gênero vem sendo definido e proposto como diretriz em políticas públicas de "inclusão social" no Brasil. Aqui, examinamos, de forma específica, a produção acadêmica sobre o tema "transversalidade de gênero em políticas públicas" entre os anos de 2004 e 2016, para descrever ênfases teórico-políticas nela prevalentes, bem como tensões e desafios apontados por esses estudos parasua efetivaimplementação. Foram examinados artigos, tesesedissertações disponiveis em bases de pesquisa virtuais, localizadas com técnicas de investigação e filtros de seleção sugeridos em estudos sobre revisão de literatura. A análise apontou que a produção sobre o tema é pequena, está aglutinada em determinadas instituições e em torno de alguns/as autores/as, e que a transversalização de gênero em políticas públicas é defendida como um dispositivo potente de promoção de igualdade que, no entanto, ainda enfrenta muitos desafios para ser efetivamente implementado.

Palavras-chave: Transversalidade de gênero. Políticas públicas. Revisão de literatura.

\section{ABSTRACT}

This paper draws from interinstitutional and multi-focus research framing some of the ways in which gender mainstreaming has been defined and proposed as a guideline for public policies of social inclusion in Brazil. We specifically examined academic production on gender mainstreaming in public policies published between the years of 2004 and 2016 in order to describe theoretical and political emphases found in these works, as well as tensions and challenges these studies point as needed to be overcome for successful implementation of policies. We collected papers, dissertations, and theses available in virtual research databases, found with research techniques and selection filters gathered from studies on literature review. This analysis has shown that there is little research on this theme, that it is concentrated in particular institutions and authors, and that gender mainstreaming in public policies is defended as a powerful device for promoting equality that, however, still has to overcome many challenges in order to be successfully implemented.

Keywords: Gender mainstreaming. Public policies. Literature review. 


\section{SOBRE ESTE ARTIGO}

0 artigo se desdobra de pesquisa interinstitucional e multifocal, inscrita nos campos dos Estudos de Gênero e Culturais pós-estruturalistas, que problematiza a transversalidade de gênero em políticas públicas no Brasil. Neste desdobramento examinamos, de forma específica, a produção acadêmica sobre o tema "transversalidade de gênero em políticas públicas" ${ }^{1}$, disponibilizada entre os anos de 2004 e 2016, em bases de pesquisas virtuais como Scielo, Portal de Teses e Dissertações da Capes e Biblioteca Digital Brasileira de Teses e Dissertações. Isso para dar conta de um dos objetivos da pesquisa, qual seja, o de descrever e discutir tanto as ênfases teórico-políticas prevalentes nesses estudos quanto as tensões e desafios neles apontados, quando se trata da operacionalização dessa transversalidade. Começamos por retomar o conceito de transversalidade de gênero, situando-o no contexto político que tornou possível o seu posicionamento como princípio organizador de políticas públicas no Brasil. Examinamos, para isso, os Planos Plurianuais (2004, 2007, 2011, 2013, 2016); as Conferências Nacionais de Políticas de Mulheres (2004, 2007 e 2011); os Planos Nacionais de Políticas Públicas para as Mulheres (PNPM de 2004-2007; 2008-2011; 2013-2015) e as Orientações Estratégicas para Institucionalização da Temática de Gênero nos Órgãos Governamentais (2011), além de textos de estudiosas que discutem desdobramentos conceituais e políticos do termo (BANDEIRA, 2003; 2005; SARDENBERG, 2010; PRÀ, 2010; LABRECQUE, 2010; LAVINAS, 2013).

A transversalidade de gênero é, usualmente, apresentada como uma estratégia proposta na IV Conferência Mundial sobre a Mulher, da Organização das Nações Unidas (ONU), realizada em 1995, em Beijing, com o objetivo basilar de promover a redução das desigualdades de gênero no mundo. Entretanto, autoras como Marie France Labrecque (2010, p. 903-4) problematizam essa apresentação, sinalizando que outros estudos e autoras/es (entre os quais ela se inclui) concordam em afirmar que o contexto de afirmação da transversalização de gênero como princípio e como estratégia, na ótica em que a vivenciamos também aqui no Brasil, "é aquele que envolve tanto o Consenso de Washington, que corresponde a uma série de programas inspirados nas abordagens de Milton Friedman e dos Chicago Boys", que defendiam o "objetivo de fazer com que o Estado deixe pleno espaço ao mercado" quanto o que ela nomeia de "era pós-consenso de Washington"; tais contextos, segundo a autora, teriam impulsionado, sobretudo a partir de 2001, a integração sistemática "do gênero ao conjunto da estratégia do Banco Mundial", colocando

\footnotetext{
${ }^{1}$ Tendo em vista as expressivas mudanças em curso no cenário político brasileiro atual, sobretudo no que diz respeito às questões que envolvem gênero e sexualidade, não é possível afirmar que a transversalização de gênero seguirá ocupando essa posição na proposição de políticas públicas. Por isso, a revisão empreendida neste artigo abrange um período que se encerra em 2016.
} 
"ênfase, a partir desse momento, na relação entre desigualdade de gênero e pobreza".

Nomeada como gender mainstreaming a noção tem sido debatida, tematizada, disputada e incorporada, desde então, em vários contextos sociais, movimentos políticos e países, e desde distintos enfoques teórico-metodológicos e práticos, o que a coloca no foco de investimentos acadêmicos e de disputas políticas no plano internacional. Por isso, não há consenso quanto à definição do conceito, o que possibilita que diferentes pontos de vista sejam colocados em relação e em disputa. Passamos, agora, a examinar alguns desses debates e disputas.

\section{2 ...DA INSTITUCIONALIZAÇÃO DA TRANSVERSALIDADE DE GÊNERO EM POLITICAS PÚBLICAS BRASILEIRAS: FRAGMENTOS}

Gender mainstreaming pode ser definido em linhas gerais, segundo o Conselho Europeu (apud LABRECQUE, 2010, p. 902), como: "[...] a (re)organização, a melhoria, o desenvolvimento e a avaliação dos processos políticos, de modo que uma perspectiva de igualdade de gênero seja incorporada a todas as políticas em todos os níveis e em todas as etapas, por todos os que têm poder de decisão". No cenário nacional, a noção de gender mainstreaming foi traduzida, primeiramente, como transversalidade ${ }^{2}$ de gênero e institucionalizou-se, com sua explicitação, como princípio organizador de políticas públicas, no texto do Plano Plurianual 2004-2007³. Sua adoção pode ser traduzida como resultado tanto de lutas lideradas por distintos movimentos feministas e de mulheres, quanto como decorrência da apropriação dessas reinvindicações por organismos internacionais como a ONU, o UNICEF (e, também, o Banco Mundial e o FMI) e que, aqui, foram rearticuladas e pactuadas pela então Secretaria de Políticas Públicas para as Mulheres (SPM). Esta, criada em 2003, no governo do então presidente Luis Inácio Lula da Silva, tinha como objetivo central promover a igualdade entre homens e mulheres e combater todas as formas de preconceito e discriminação. Afirmando que "a questão de gênero está incluída nas políticas dos três níveis de Governo" e que a "crescente mobilização da sociedade civil na busca de igualdade entre homens e mulheres, em termos de direitos e obrigações" tem demandado mudanças que revertam as profundas situações de assimetria e de desigualdade social no País, argumentou-se que estas deveriam ser viabilizadas "a partir de um processo contínuo de cooperação transversal entre a SPM e os demais

\footnotetext{
2 O uso deste termo será problematizado, no Brasil, em anos posteriores, sugerindo-se o uso de transversalização de gênero. Por isso os dois termos aparecem no texto, exatamente para visibilizar estas disputas.

3 Plano de médio prazo que estabelece diretrizes, objetivos e metas a serem cumpridas pelo Governo Federal ao longo de um período de quatro anos.
} 
Ministérios, a sociedade civil e a comunidade internacional" 4 .

Nesse contexto, os três PNPM (2004-2007; 2008-2011; 2013-2015) reafirmaram como objetivos: 0 fortalecimento da autonomia das mulheres em todas as dimensões da vida; a busca da igualdade efetiva entre mulheres e homens, em todos os âmbitos; o respeito à diversidade e o combate a todas as formas de discriminação; a afirmação do caráter laico do Estado; a universalidade dos serviços e benefícios ofertados pelo Estado; a promoção da participação ativa das mulheres em todas as fases das políticas públicas; a transversalidade como princípio orientador de todas as políticas públicas. (BRASIL, 2013).

O Plano Plurianual 2004-2007 estabeleceu três megaobjetivos, com o intento de incluir um espectro amplo de sujeitos desassistidos em seus direitos. 0 primeiro deles, denominado de Dimensão Social, apontou como nono desafio "promover a redução das desigualdades de gênero" (BRASIL, 2003, p. 158). O plano assumiu "o princípio da transversalidade de gênero na formulação e desenvolvimento das políticas públicas, incluindo-se, aí, todos os setores de atuação e segmentos de poder" (BRASIL, 2003, p. 90). 0 termo transversalidade de gênero foi utilizado apenas uma vez em todo o Plano 20042007, porém sua redação explicita a relação com a promoção da igualdade de gênero, direcionando suas ações principalmente para as mulheres, nele posicionadas como sujeitos menos assistidos, uma vez que "ainda subsiste [grande] hierarquização por sexo nos mais diferentes campos da vida social" (BRASIL, 2003, p. 158). Este direcionamento levou em conta, principalmente: a prevalência de elevados índices de violência contra a mulher, especialmente os de violência doméstica; a disparidade entre os salários de homens e mulheres, apesar de elas terem grau de escolarização mais elevado; a evidência de uma dupla desigualdade, uma vez que mulheres negras recebem salários ainda menores do que as mulheres brancas. O documento destaca, também, que "entre a população que se concentra abaixo da linha da pobreza, as mulheres são as mais pobres, vivendo em condições de extrema miserabilidade, tendo negados os direitos de acesso à educação, ao mundo do trabalho, aos serviços de saúde e à habitação" (BRASIL, 2003, p. 91). Não há menção, ao longo do documento, a mulheres trans. 0 texto refere-se à mulher negra, pobre, pouco escolarizada, mas cisgênero, ou seja, aquela que se reconhece como pertencendo ao gênero ao qual foi involuntariamente designada quando nasceu. 0 mesmo acontece nos planos seguintes. Este é um ponto relevante que se destaca e repercute, com diferentes efeitos, nos textos programáticos das diferentes políticas examinadas e que constitui, também, um ponto de profundas divergências no interior dos próprios feminismos, como se pode ver em um dos editoriais da Revista Labrys $(2018)^{5}$.

\footnotetext{
${ }^{4}$ Disponível em: <http://www.spm.gov.br/sobre/a-secretaria>.

${ }^{5}$ Disponível em: <https://www.labrys.net.br/labrys31/informacoes/informations.htm>. Acesso em: 04 abr. 2018.
} 
O termo transversalidade de gênero não foi utilizado nos dois Planos Plurianuais seguintes (BRASIL, 2008; 2011), apesar destes seguirem indicando a inclusão da dimensão de gênero nas políticas públicas e reafirmarem o foco nas mulheres, tomando como referência, sobretudo, "[...] o enfrentamento da violência contra as mulheres, com a implementação de políticas em áreas estruturantes, integradas ao Pacto Nacional pelo Enfrentamento da Violência contra as Mulheres" (BRASIL, 2008, p. 15). Já o texto propositivo do Plano Plurianual para 2016-2019 recuperava, com sua redação, a ideia de transversalidade de gênero no tópico "Políticas Para as Mulheres: Promoção da Igualdade e Enfrentamento à Violência" (BRASIL, 2015). Utilizam-se, nesse texto mais recente, expressões como "tratamento transversal" ou "transversalidade", que aparecem de forma reiterada nesta versão do documento, sem acréscimo do termo gênero. Diferentemente do Plano de 2004-2007, quando o conceito apareceu uma só vez sem explicitação conceitual, o documento vigente afirma

[...] que as questões de gênero ganharam especial destaque no Brasil a partir da criação, em 2003, da Secretaria de Políticas para as Mulheres - SPM, consolidando a institucionalização das políticas de gênero e o tratamento transversal dessas questões no âmbito do governo federal, ao reunir em um órgão a competência de formular, coordenar e articular as políticas de promoção da igualdade entre mulheres e homens. (BRASIL, 2015, p. 83).

A transversalidade também foi o foco do I Plano Nacional de Políticas para as Mulheres (PNPM), que assumiu a transversalidade como princípio organizador. 0 objetivo explícito deste Plano era o de "promover a transversalidade das políticas para mulheres e a igualdade de gênero" (BRASIL, 2004, p. 13). Já o III PNPM (2013) resgatou elementos do Plano Plurianual 2004-2007 defendendo a necessidade de promover a equidade entre os gêneros pela via da promoção de autonomia das mulheres. Assim, 0 Plano Plurianual de 2004 segue direcionando os princípios orientadores das Políticas Nacionais para as Mulheres: "Autonomia das mulheres em todas as dimensões da vida [...]" (BRASIL, 2015, p. 84).

Além disso, o III PNPM listou uma série de outros princípios fundamentais para reafirmar a "transversalidade como princípio orientador de todas as políticas públicas" (BRASIL, 2015, p. 84). A afirmação da transversalidade como uma estratégia para fomentar a autonomia é apresentada de modo particular no Capítulo 1, na forma de um construto teórico, pautado pelo conceito de autonomia econômica, e como um construto prático, priorizando ações voltadas para a educação e empregabilidade de mulheres pobres. Expressa-se, ai, a economização do social como proposta para operar com a transversalidade de gênero, ou seja: desenvolver a autonomia econômica das mulheres e reduzir as desigualdades de gênero (cf. TRINDADE; SCHWENGBER, 2017). Da mesma maneira, o capítulo "Cultura, esporte, comunicação e 
mídia", desse mesmo PNPM, permite tensionar certo alargamento da concepção de esporte e de lazer como um direito civil articulado à noção de autonomia econômica, uma vez que sugere o investimento em ações que visam o uso igualitário de espaços e equipamentos de esporte e lazer e o reconhecimento da profissionalização esportiva para as mulheres, tendo como princípio orientador a igualdade de gênero (cf. BERTOLLO; SCHWENGBER, 2017). A relação aqui estabelecida entre transversalidade de gênero e uma certa forma de economização do social vai ao encontro da análise feita por Labrecque (2010, p. 905, com apoio em SOHAL, 2005,) ao examinar a relação entre transversalização de gênero e instrumentalização das mulheres. Com o termo, a autora problematiza

[...] a forma sob a qual as recomendações internacionais chegam às organizações de desenvolvimento, seja sob a forma de um conjunto de fórmulas e maneiras de agir (package) que favorecem uma aplicação mais mecânica das medidas visando à igualdade de gênero, ou retomando uma dicotomia que está no centro da instrumentalização a satisfação das necessidades práticas de gênero prevalece sobre a dos interesses estratégicos de gênero (p. 905).

Do ponto de vista de sua visibilidade, do I PNPM (2004) à terceira edição do mesmo documento em 2013, houve um aumento significativo no uso explícito da palavra "gênero", ao invés do termo políticas destinadas às mulheres ${ }^{6}$. Ao mesmo tempo, o termo "transversalidade de gênero" deixa de ser referido apenas com o sentido de "gestão transversal" e passa a ser utilizado com fins estratégicos a partir do documento de Orientações Estratégicas para Implementar a Transversalidade de Gênero nos Órgãos Governamentais (BRASIL, 2011). Este documento foi publicado com a finalidade de reforçar a incorporação do "[...] recorte de gênero para além da instituição responsável pela coordenação de políticas para as mulheres".

Assim, os documentos até aqui citados oscilam entre o uso dos termos gênero e mulheres, e a transversalidade de gênero parece, por vezes, ser usada como sinônimo da incorporação das mulheres nas políticas públicas, acionando, deste modo, uma perspectiva específica de gênero. Com relação a isso, Lourdes Bandeira (2003, p. 1) já alertava que políticas e programas públicos direcionados de forma explícita para a transformação de desigualdades de gênero deveriam se diferenciar de políticas e programas direcionados para mulheres, uma vez que as primeiras precisariam não só considerar, mas acessar "necessariamente, a diversidade dos processos de socialização de homens e mulheres, cujas consequências se fazem presentes, ao longo da vida, nas relações individuais e coletivas".

\footnotetext{
${ }^{6}$ No primeiro Plano Nacional de Políticas para as Mulheres (2004), a expressão gênero é usada uma vez em cada página. Já no terceiro Plano (2013), ela aparece pelo menos duas vezes em cada página.
} 
Ainda, no plano teórico-conceitual, a partir de um dado momento, o entendimento até aqui referido para o termo transversalidade passa a ser tensionado, no contexto brasileiro. Cecilia Sardenberg (2010), por exemplo, passou a chamar atenção mais fortemente para o fato de que não há consenso em torno da tradução da expressão gender mainstreaming, e que isso poderia ser um problema para seu uso nas análises empreendidas: deveria ela ser traduzida como transversalidade ou transversalização de gênero, uma vez que os dois termos aparecem indistintamente nas políticas e, também, nas publicações que discutem essa temática? A autora, assim como Jussara Prá (2010) sinalizaram, então, que há uma diferença no sentido atribuído a esses termos, uma diferença que implica, inclusive, uma disputa nos modos de implementação da política. Segundo Sardenberg "[...] a transversalidade das hierarquias de gênero é um fato amplamente constatável. Daí porque a necessidade da transversalização da perspectiva das relações de gênero nas políticas públicas: para garantir a promoção social, econômica, política, cultural, etc. das mulheres" (SARDENBERG, 2010, p. 47).

Trata-se, aqui, de uma distinção conceitual com importantes implicações práticas: a transversalidade estaria sempre em operação, na medida em que assumimos que o gênero é operador de poder e um organizador do social e da cultura (o que, em convergência com essa abordagem, temos nomeado e descrito, em vários dos estudos realizados em nosso grupo, como generificação do social). Seria, pois, necessário entender como o gênero funciona nos diferentes contextos e relações para, então, intervir intencionalmente, objetivando modificar tais formas de funcionamento. É a esta proposta de intervenção intencional, por meio da articulação planejada de políticas públicas, que as autoras passam a designar como transverzalização. Torna-se então importante atentar para o que diz Sylvia Walby (2003, p. 2) quando usa o termo transversalização de gênero. Segundo a autora, o termo engloba, ao mesmo tempo, " um conjunto teórico e um conjunto de práticas". Como conjunto teórico, "a transversalização do gênero [demanda] revisar os conceitos-chave que possibilitam um entendimento mais adequado do mundo enquanto elemento estruturado em função do gênero" - o que remete, justamente, à noção de gênero como organizador do social. E como conjunto de práticas, "a transversalização do gênero constitui uma nova estratégia para o desenvolvimento como processo estruturado em função do gênero."

Nesta direção, cabe ainda sinalizar outra diferença conceitual e operativa importante que diz respeito ao uso indistinto, em muitos dos documentos normativos das políticas em foco, dos termos equidade e igualdade, quando também eles englobam dimensões conceituais e dimensões político-práticas, que ensejam o entendimento de que a transversalização de gênero, por se caracterizar como uma intervenção intencional e planejada deveria funcionar como uma estratégia que investe na equidade para, assim, alavancar o objetivo dessas políticas que seria a promoção da igualdade de gênero. Tomar 
e operar explicitamente a transversalização como estratégia de equidade para alavancar a igualdade de gênero não só explicaria, como justificaria o foco prioritário em mulheres em muitas das políticas que se inscrevem nesse princípio, justamente na direção do alerta feito por Bandeira (2003), anteriormente citado. Na revisão de literatura que realizamos, encontramos poucos estudos que se debruçam sobre esses entendimentos e desdobramentos conceituais, de forma mais exaustiva. Passamos, agora, à revisão da produção acadêmica que realizamos, começando por descrever o percurso metodológico que, nele, traçamos.

\section{SOBRE O PERCURSO METODOLÓGICO}

Denominamos a metodologia de pesquisa aqui empregada como revisão de literatura, inspirada nos aportes teóricos utilizados em estudos sobre "estado da arte" ou "estado do conhecimento". Tratase, neste caso, de um tipo de procedimento que não se restringe a mapear uma produção acadêmica existente, pois está interessado, também, em categorizar e analisar essa produção acadêmica.

Segundo Delma Pillão (2009), o termo estado da arte não constitui uma unidade conceitual fechada, pois é compreendido por diferentes pesquisadores em diferentes perspectivas "[...] como uma modalidade de pesquisa adotada e adaptada/interpretada" de acordo com questões específicas de pesquisa. Mesmo utilizando "diferentes denominações - estado da arte, estado do conhecimento, mapeamento, tendências, panorama, entre outras [...]", as pesquisas que adotam esta metodologia possuem um fio condutor que é comum a todas elas, qual seja, "a busca pela compreensão do conhecimento acumulado em um determinado campo de estudos delimitado no tempo e no espaço geográfico" (PILLÃO, 2009, p. 45). Marisol Melo destaca também que:

Esses estudos de mapeamento do estado de conhecimento de uma determinada área acadêmica, em diferentes épocas e lugares, buscam identificar e analisar tendências temáticas e metodológicas e principais resultados, tomando como material de análise estudos específicos, traduzidos em artigos, publicações em anais e, especialmente, em dissertações e teses acadêmicas (MELO, 2006, p. 62).

Tais estudos procuram inventariar e sistematizar a produção acadêmica em certa área de conhecimento ou sobre determinado tema - caso deste artigo, que se interessa por inventariar as análises sobre transversalidade/transverzalização de gênero nas políticas públicas -, buscando identificar disposições e arranjos. Em outras palavras, "não se restringem a identificar a produção, mas analisá-la, categorizá-la e revelar os múltiplos enfoques e perspectivas" (ROMANOWSKI; ENS, 2006, p. 39). Nessa direção, "[...] organizar, esclarecer e resumir as principais obras existentes, bem como fornecer citações completas 
abrangendo o espectro de literatura relevante em uma área [...]" (ROMANOWSKI; VOSGERAU, 2014, p. 167) torna-se um procedimento metodológico importante nestes estudos. $\mathrm{E}$, para que esse procedimento se torne possivel, é necessário delimitar um recorte temporal a partir do qual faz sentido iniciar o inventário, já que estas pesquisas podem fornecer um panorama histórico sobre o tema e sua variação no tempo.

Num primeiro movimento de revisão feito por nós, utilizamos descritores que deveriam constar ou nos títulos, ou nos resumos, ou nas palavras-chave dos trabalhos encontrados. Realizamos essa busca utilizando a estratégia da permuta entre as palavras/conceitos: Igualdade, Equidade, Políticas Públicas, Transversalizar (Transversalidade/Transversalização/Gender Mainstreaming). A permuta, utilizada por Jonas Neves et al. (2014), consiste em juntar mais de um conceito-chave no campo de pesquisa das plataformas virtuais, com intuito de especificar o tipo de material empírico encontrado e, portanto, potencializar a análise futura. Permutamos, então, o conceito de transversalidade/transversalização de gênero e políticas públicas com as outras palavras-chave, a fim de nos aproximarmos do material empírico que nos interessava para a pesquisa.

A presença dos descritores que elencamos não garantia, no entanto, que o conceito de transversalidade de gênero estivesse sendo tematizado nos estudos. Por isso, elaboramos três filtros de seleção dos textos para melhor delimitar o material empírico. 0 primeiro filtro tratou de eliminar publicações sem referências completas e, também, formatos irrelevantes para o estudo, como resenhas, por exemplo. 0 segundo filtro consistiu na leitura dos títulos, resumos, palavras-chave e referências. Com isso, algumas publicações foram deixadas de lado e mantidas em um arquivo separado, para onde, conforme indicação de Fernanda Treinta et al. (2014), foram destinados os materiais rejeitados pelos filtros, mas que devem ser conservados pelos/as pesquisadores/as até a finalização da pesquisa, caso haja necessidade de retornar a eles para empreender uma leitura completa. No terceiro filtro realizamos uma primeira leitura dos textos e eliminamos, neste momento, artigos/teses/dissertações que se distanciavam da nossa temática de pesquisa ou que não tematizavam a transversalidade de gênero ao longo do texto. 0 que demanda explicar que, embora alguns trabalhos tenham apresentado a palavra transversalidade ou um de seus desdobramentos no resumo, no título ou nas palavras-chave, esta não apareceu no corpo do texto para refletir sobre sua incorporação nas políticas públicas. Algumas vezes o termo nem era citado ao longo do trabalho ou aparecia só nas conclusões com uma única referência7. Tendo feito essas três

\footnotetext{
7 Entendemos, no decorrer da pesquisa, que muitos trabalhos, que analisam modos pelos quais o gênero atravessa e constitui políticas públicas, estão fazendo uma reflexão sobre transversalidade/transversalização de gênero. Esse é o caso de todas as pesquisas anteriormente produzidas em nosso grupo de insvetigação. Entretanto, como o descritor não é mencionado, tais trabalhos ficaram fora desta revisão, e essa opção, consequentemente, reduziu o número de trabalhos localizados e visibilizados aqui.
} 
seleções, criamos um portfólio dessas publicações que foram devidamente fichadas.

Assim, encontramos nas três plataformas de pesquisa (Scielo, Portal de Teses e Dissertações da Capes, Biblioteca Digital Brasileira de Teses e Dissertações) 97 publicações relacionadas às nossas palavras-chave. Com a aplicação dos filtros de seleção, elegemos ao todo 12 publicações brasileiras e duas mexicanas para análise. Ou seja, selecionamos 14 publicações nesta revisão primária.

Notamos, naleitura completa dos trabalhos inventariados, quehaviaestudos importantes referenciados ao longo dos textos, que balizavam a argumentação das teses, dissertações e artigos e que, ao mesmo tempo, não foram encontrados em nossa busca, uma vez que não estavam nas plataformas de busca utilizadas. Assim, para ampliar nosso escopo, fizemos uso do procedimento chamado de revisão inversa. A revisão inversa, de acordo com Ana Marote et al. (2012, p. 3), "é um método de seleção de documentos a partir da bibliografia dos estudos primários, onde se procuraram artigos utilizados por esses mesmos estudos [...]". Dessa forma, investimos nas referências bibliográficas dos trabalhos inventariados para localizar produções que têm orientado teórica e analiticamente os estudos sobre transversalidade de gênero e políticas públicas. Em função da revisão inversa, incluímos na lista do material empírico a pesquisa de Lourdes Bandeira (2005) - produzida e publicada no âmbito da SPM - já que foi utilizada como referência central em grande parte dos trabalhos acadêmicos aqui apresentados. Adicionamos, ainda, mais oito artigos ao nosso escopo, sendo que mais da metade desses materiais foram publicados internacionalmente. Por isso, resolvemos incorporar os trabalhos estrangeiros de modo geral. Com a revisão inversa totalizamos, então, 22 textos para análise, sendo que 14 deles são brasileiros, 03 são da Inglaterra, 03 do México, sendo localizadas, ainda, produções na Argentina, na Venezuela e nos Estados Unidos. A produção brasileira está discriminada abaixo por instituição.

- Universidade de Brasília: 2

- Pontifícia Universidade Católica do Rio Grande do Sul: 1

- Universidade Federal da Paraíba: 1

- Universidade Federal do Rio Grande do Sul: 1

- Universidade de São Paulo: 1

- Fundação Getúlio Vargas: 2

- Universidade Federal de Santa Catarina: 3

- Universidade Federal da Bahia: 2

- Secretaria Especial de Política para as Mulheres (SPM): 1 


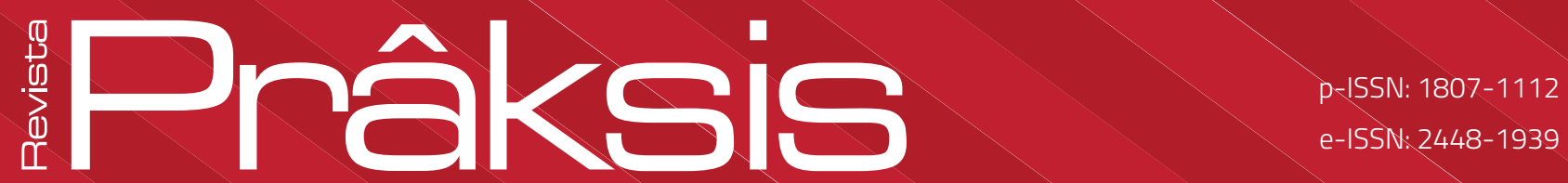

Os artigos com essas temáticas também se concentram em alguns periódicos: dos sete artigos selecionados antes dos filtros na plataforma Scielo, quatro foram publicados na Revista Estudos Feministas (2010), mas dois deles não passaram por todos os filtros por não tematizarem a transversalidade ao longo do trabalho, e dois foram publicados em revistas no México por pesquisadoras estrangeiras. ${ }^{8}$

Gráfico 1 - Distribuição dos trabalhos brasileiros por ano

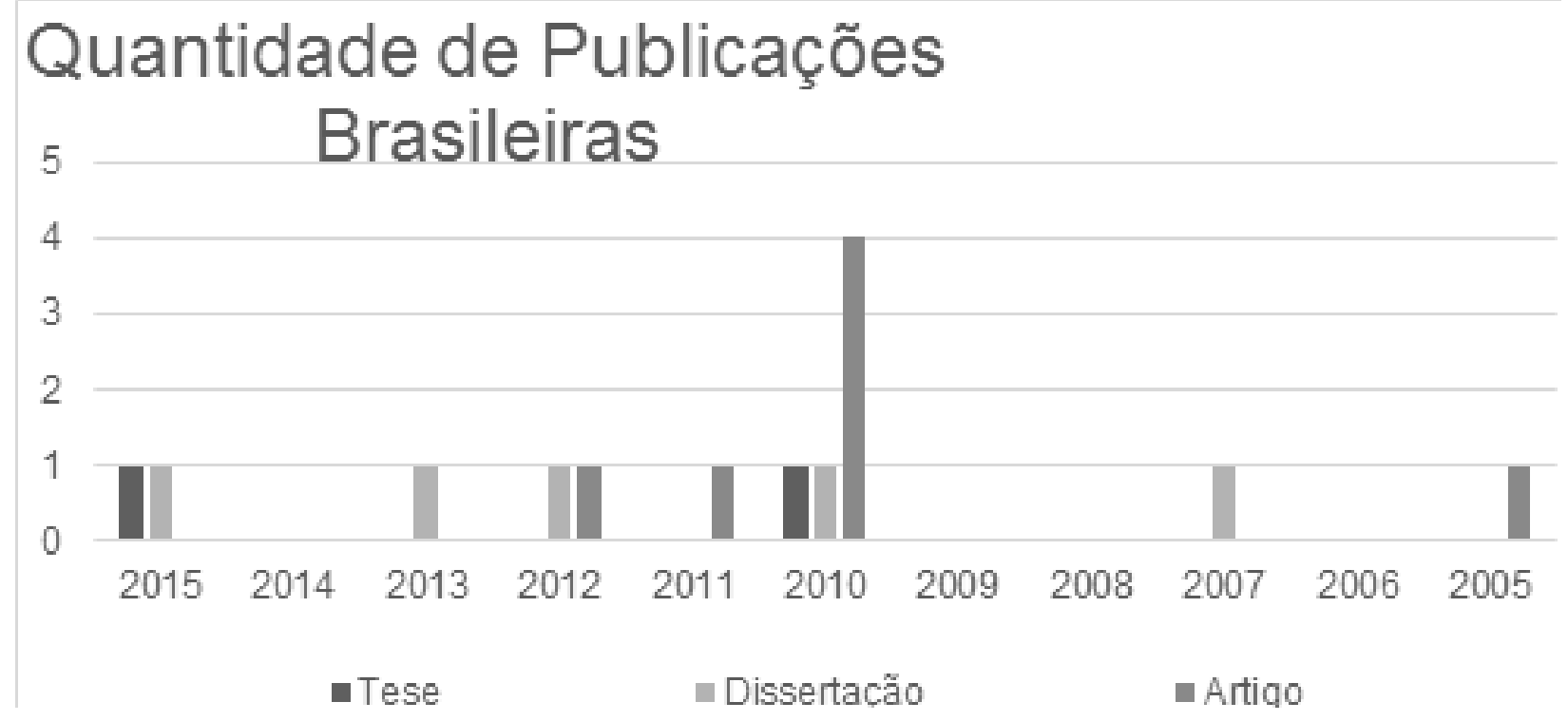

${ }^{8}$ Faremos uso da flexão de gênero no feminino, a partir daqui, em função de termos apenas um trabalho produzido por homem. 
Gráfico 2 - Distribuição dos artigos estrangeiros por ano

\section{Quantidade de Publicações Estrangeiras da Revisão Inversa}

5

4

3

2

1

0

$\begin{array}{lllllllllll}2015 & 2014 & 2013 & 2012 & 2011 & 2010 & 2009 & 2008 & 2007 & 2006 & 2005\end{array}$


A partir da leitura do Gráfico 1, notamos que há, aparentemente, lacunas temporais na produção que tematiza a transversalidade de gênero em políticas públicas no Brasil. Após a primeira publicação sobre o tema, de Lourdes Bandeira, em 2005, há um espaço de dois anos até a próxima publicação, sendo esta a primeiradissertação. Atéapublicaçãodaprimeiratese, passam-secincoanos. Nota-se, pelocruzamentodos dados, que nenhuma das teses e dissertações gerou, ainda, a produção de artigos nas bases pesquisadas. Considera-se, dentro desta questão, que a publicação do artigo de Bandeira foi uma encomenda da SPM, no intuito de fortalecer o conceito e avançar na transversalidade da perspectiva de gênero nas Políticas Públicas - o que explica sua publicação apenas um ano após a noção da transversalidade de gênero aparecer de modo explícito no texto do Plano Plurianual 2004-2007. Além disso, sabe-se que teses e dissertações precisam de um tempo mínimo de produção até sua publicação, tempo que se encaixa exatamente no tempo de publicação da primeira dissertação e da primeira tese, como mostra o gráfico.

As publicações estrangeiras, por terem sido incorporadas, em sua maioria, pela revisão inversa, não dão um panorama geral sobre o total da produção e suas distribuições anuais, tal como foi possível fazer com as publicações brasileiras. Ainda assim, a sua sistematização é muito importante para a nossa análise, uma vez que elas são os referenciais teóricos das produções brasileiras que tematizam a transversalidade de gênero.

Nesse sentido, pensamos ser significativa a comparação, em especial, no ano de 2005: a produção rastreada nas pesquisas internacionais em comparação aos outros anos (conforme o gráfico) indica que, nesse ano, os estudos que tematizavam a transversalidade de gênero já estavam em pauta nas agendas de pesquisa de alguns países, especialmente nos europeus. No caso brasileiro, em 2005 temos a publicação de Bandeira, o que se justifica, considerando que o princípio da transversalidade entra, oficialmente, no domínio da política brasileira somente em 2004. 0 artigo de Lourdes Bandeira, sendo pioneiro na discussão sobre o tema, é utilizado em todas as teses e dissertações localizadas como parte - ou totalidade - do referencial teórico sobre a transversalidade de gênero. A autora, como uma das mais importantes referências sobre a temática, é também presença destacada nas bancas das teses e dissertações que localizamos.

Duas publicações que também são balizadoras da reflexão sobre a noção de transversalidade nas políticas públicas no Brasil, embora não se caracterizem como trabalho de pesquisa acadêmica resultado de tese ou dissertação, são os textos de Jussara Reis Prá e Cecília M. B. Sardenberg, publicados em 2010 pelo Núcleo de Estudos Interdisciplinares sobre a Mulher, na Coleção Bahianas. O primeiro tem como foco a temática da transversalização de gênero nas políticas públicas, "abordagem hoje imperativa pela necessidade de contemplar as mulheres como sujeitos de direito e qualificar cenários institucionais voltados a promover e expandir a cidadania feminina" (PRÁ, 2010, p. 14-15). 0 segundo artigo se propõe 
"[...] a adentrar os meandros do debate atual sobre transversalização, refletindo sobre os aportes teóricos, delineando seus aspectos práticos e identificando alguns dos problemas e limitações dessa estratégia na construção da equidade de gênero" (SARDENBERG, 2010, p. 40).

A partir da revisão inversa, localizamos, também, documentos normativos oficiais que procuravam orientar a incorporação da transversalização de gênero em políticas públicas no exterior. Um exemplo disso é a organização de um grupo de especialistas em mainstreaming pelo Conselho Europeu (STRASBOURG, 1998) que, dentre outras coisas, pretendia balizar conceitual, metodológica e praticamente a transversalização de gênero nas políticas públicas. No Brasil, como já apontamos, o primeiro documento a citar a transversalidade foi publicado em 2004 (BRASIL, 2004), ao passo que o primeiro documento a balizar conceitual e metodologicamente a transversalidade como estratégia foi publicado em 2011, no documento de Orientações Estratégicas (BRASIL, 2011).

Esses diferentes tempos parecem indicar que a incorporação brasileira, ou da América Latina em geral, demandou investimentos que podem ser de ordem política e/ou econômica mais complexas, já que não foi encontrado nenhum tipo de documento similar ao europeu para outros países da América Latina. Não podemos desconsiderar, no entanto, que mesmo antes de 2004 havia um esforço, por parte de grupos e comissões que discutiam e/ou planejavam ações governamentais no Brasil, de incluir nas agendas políticas e nos textos oficiais a promoção da igualdade ou da equidade de gênero. Mesmo sem usar o termo, podemos pensar no princípio da transversalidade operando aí.

A Plataforma de ação adotada em Beijing e reforçada em Beijing mais cinco (Beijing, 1995/2000) confirmou e materializou "[...] o conceito de transversalidade de gênero como uma estratégia básica de promoção da equidade, considerando ainda que todas as estratégias anteriormente adotadas não haviam sido bem sucedidas" (BANDEIRA, 2005, p. 12). Talvez movimentos internacionais sucessivos (como Beijing, 1995, 2000 e 2005, por exemplo), que buscaram intensamente alavancar estratégias para a institucionalização da perspectiva de gênero nos órgãos governamentais, possam ter impulsionado a produção internacional em 2005.

\section{TRANSVERSALIDADE DE GÊNERO NAS PESQUISAS ACADÊMICAS: CONVERGÊNCIAS E DIVERGÊNCIAS, RECORRÊNCIAS E CONTRADIÇÕES}

Nesta seção, após a leitura dos textos selecionados, procuramos atender, mais especificamente, ao objetivo proposto na apresentação deste texto, qual seja: analisar como as pesquisadoras e pesquisadores têm tematizado a transversalidade de gênero quando analisam a produção e implementação de políticas públicas. 
Constatamos, como já foi apontado, que muitas pesquisadoras tematizam a transversalidade de modos distintos, dentre outras coisas, por que os estudos adotam perspectivas teóricas distintas. 0 que quer dizer que o significado do "conceito de transversalidade varia de acordo com [a posição teóricopolítica assumida pelo] sujeito da fala", como nos aponta Fernanda Papa em sua dissertação de mestrado (PAPA, 2012, p. 60). Entendemos que, como vivemos em tempos instáveis, mutáveis e permeados por disputas, uma multiplicidade de vozes se coloca produzindo discursos que se multiplicam e se transformam, que ora convergem ora divergem sobre um mesmo tema. A transversalidade não escapa destas discursividades que, nas arenas política, acadêmica e social, disputam espaço de afirmação e legitimidade entre si, sendo esta diversidade de posições uma das marcas potentes do campo dos estudo feministas. Ainda, a temática é emergente no cenário tanto político quanto acadêmico, reunindo pesquisadores/as com diferentes inserções teóricas.

Ao mesmo tempo em que estas diferentes inserções e vozes fazem falar a necessidade da transversalidade/trasnversalização de gênero e multiplicam olhares, também produzem tensões sobre o entendimento do termo e de sua operacionalização. Papa (2012, p. 55) aponta que "ainda há limites a superar, pois, por se tratar de algo relativamente recente para a gestão pública, os instrumentos para a estratégia transversal ainda estão sendo criados e testados, em meio a resistências, próprias de culturas organizacionais cristalizadas".

Bandeira aponta, em um dos estudos referência nessa temática, que foi no contexto dos movimentos feministas, a partir da década de 1980, e em profundas discussões sobre como uma política mundial de promoção da igualdade e de oportunidade das mulheres poderia se efetivar, bem como na Conferência de Beijing em 1995 que, finalmente, "essa estratégia foi designada de 'gender mainstreaming', reconhecida como transversalidade de gênero" e assim adotada nos documentos produzidos desde então (BANDEIRA, 2005, p. 10). Visava (e visa), segundo a autora, à melhoria de vida das mulheres em todas as dimensões "[...] econômica, política, cultural e social, com repercussões nas esferas jurídicas e administrativas [...]" (BANDEIRA, 2005, p. 10). Era (eé) uma estratégia conceitual-política pensada por mulheres para mulheres, visando a igualdade entre os sexos, mas considerando as singularidades das mulheres e dos homens, bem como as singularidades entre mulheres. Para Priscila Andrade (2007), apesar da proposição da transversalidade como estratégia de equidade para promover igualdade ser direcionada para mulheres, elas são poucas atuando no cenário das políticas públicas. Esta pesquisadora aponta, com isso, que há um problema de representatividade aí, que afeta a efetivação da transversalidade pautada na superação da desigualdade entre homens e mulheres. A transversalidade seria tomada, assim, como um instrumento estratégico para a gestão de políticas públicas para mulheres no Brasil. Mas, segundo Papa (2012), o que 
temos sobre transversalidade está distante do que foi normativamente recomendado. A autora afirma que há caminhos para concretizar a tarefa e os pauta detalhadamente em seu texto.

Diferentes trabalhos analisados apontam que programas e ações governamentais idealizados e executados sem a adoção da perspectiva da transversalidade podem ser alguns dos elementos que impedem a consolidação do princípio de igualdade de oportunidades. Entre as publicações consideradas, há concordância de que a transversalidade de gênero ainda enfrenta obstáculos para se institucionalizar, de fato, nas políticas públicas. Albert Serra (2005), pesquisador espanhol, por exemplo, argumenta que se faz uma má utilização do instrumento que chamamos de transversalidade, uma vez que não estaríamos utilizando-o como um instrumento organizativo das políticas, e sim como uma forma de olhar para elas. Além disso,

[...] se está depositando expectativas muito grandes na capacidade da gestão transversal para resolver desafios organizativos e políticos no âmbito da melhoria e da modernização das organizações públicas. Toda expectativa incorpora um inevitável grau de frustração, especialmente se isso se refere a desenvolvimentos organizativos; sem dúvida, o nível de frustração previsível aumenta proporcionalmente ao grau de desajuste da expectativa a respeito da realidade construída. No caso das formulações atuais da gestão transversal, este desajuste é uma fonte inevitável de frustração. (SERRA, 2005, p. 3, tradução nossa).

Manuela Lombardo (2005) reforça esta ideia e afirma que o problema da falta de operacionalização da transversalidade de gênero está ligado à perda do seu caráter revolucionário. Para fazer com que o instrumento da transversalidade de gênero fosse aceito, os adeptos do gender mainstreaming teriam silenciado e/ou diminuído sua radicalidade, de modo a fazê-lo ser aprovado na agenda política, tornando o conceito vago. Além disso, para Lombardo (2005) e Lombardo e Petra Meier (2006), a visão patriarcal também estaria fortemente presente na negação e/ou diminuição dos preceitos acordados na IV Conferência Mundial sobre a Mulher, quais sejam: a institucionalização da transversalidade de gênero e o empoderamento das mulheres.

A adoção da transversalidade de gênero, como aponta Priscila de Andrade (2007, p. 33), "[...] constitui um importante mecanismo de reconhecimento da diversidade, diferença e desigualdades existentes entre os diversos segmentos populacionais [...]". Entretanto, os trabalhos também apontam que as políticas, de modo geral, ainda investem na homogeneização do atendimento e do cuidado. E que homens e mulheres, independente de qualquer outro aspecto identitário, continuam sendo tratados do mesmo modo, não havendo atenção às peculiaridades entre os diferentes gêneros e suas especificidades sociais.

Lourdes Bandeira destaca que o Plano Plurianual 2004-2007 recomendou a garantia do recorte 
transversal não só de gênero, mas de "raça/etnia, geração, pessoa portadora de necessidade especial e orientação sexual na formulação e implementação de políticas públicas" (BANDEIRA, 2005, p. 28), e tal colocação fortalece o argumento de Priscila de Andrade (2007).

Verónica Vázquez-Garcia (2011, p. 114) reafirma que a proposta da transversalidade constitui um movimento transnacional, ou seja, um movimento "de redes e agências que têm transformado o discurso universal de direitos humanos assim como o conceito tradicional de Estado-nação, já que seus principais atores são transfronteiriços". Assim, seria possível dizer que a transversalização (como estratégia de promoção de igualdade em suas diferentes dimensões) tem uma intencionalidade que ultrapassa fronteiras territoriais e políticas (WALBY, 2005 apud VÁZQUEZ-GARCIA, 2011, p. 114, tradução nossa).

Esta autora e Juana María Gil Ruiz (2011) defendem que os problemas de operacionalização da transversalização estão no interior das próprias políticas públicas. Cada uma dessas pesquisadoras trabalhou com uma política específica em sua análise, mas ambas criticam o caráter vertical com que esse instrumento tem sido incorporado. Segundo Ruiz (2011, p. 264, tradução nossa):

De nada serve um esforço legislativo para incorporar os IEIG [Informe de Observaciones del Informe de Evaluación del Impacto de Género] - embora isso seja desejável- se os últimos operadores, as pessoas que têm de agir carecem de conhecimento e de compromisso que implica no novo direito antidiscriminatório. Nem a perspectiva de gênero, uma perspectiva complexa que incorpora categorias técnicas que eles têm de estudar, pode ficar vinculada a uma mera sensibilidade, nem é tão simples como agregar a palavra "mulheres" aos discursos ou análises da realidade, supostamente, 'com perfil de gênero'.

Haveria, nesta perspectiva, uma necessidade de operar com a transversalização de gênero de forma mais horizontal, implicando uma "melhor coordenação e um trabalho conjunto por parte dos responsáveis de toda política setorial, incorporando o Gender Mainstreaming e uma maior sensibilização, conscientização e formação em gênero de todos os envolvidos [...]" (RUIZ, 2011, p. 267, tradução nossa).

Nessa mesma direção, Caroline Moser e Annalise Moser (2005) pontuam que "compromissos políticos para a transversalização de gênero frequentemente evaporam nos processos de planejamento e implementação" (MOSER; MOSER, 2005, p. 15, tradução nossa). Para elas, essas dificuldades acontecem devido a problemas com a capacitação de funcionários, tradições culturais enraizadas e à incorporação da perspectiva de gênero e o tratamento da igualdade de gênero como um processo separado da política.

Diferentes autoras consideram que houve "avanços" na abordagem de gênero. Todavia, há um longo caminho a ser trilhado para que não se fique apenas no discurso, na incorporação de modos politicamente mais corretos de dizer, caracterizando gênero como "um mero termo no vocabulário técnico do 
planejamento" (ANDRADE, 2007, p. 112). Ou, ainda, como sinalizam Dagmar Meyer e Cols (2008, p. 40), ao examinarem a implementação do PAIF (Programa de Atenção Integral à Família) em um dado contexto, mesmo quando o gênero é incorporado, isso se faz

[...] de forma restrita e simplificada ao viés dos papéis hegemonicamente atribuídos a mulheres e a homens, mães e pais, ou com foco em traços de personalidade e características biológicas coladas ao ser homem e ao ser mulher. Isso explica uma certa ênfase das ações na correção e/ou reforço de algumas dessas características, que deveriam ser naturais mas precisam ser estimuladas (por exemplo, educar mulheres para serem mães cuidadosas e amorosas que deveriam estar dispostas, sempre, a colocar as necessidades de seus filhos e filhas acima das suas).

Nessa direção, Sylvia Walby (2005) sinaliza que há uma questão importante em jogo. Segundo ela, a discussão sobre a transversalização de gênero tem dificuldades de avançar em pesquisas e ações institucionais porque não há, assim como nos próprios estudos de gênero, consenso sobre a perspectiva de inclusão a ser adotada: será ela a partir da equidade, da igualdade, da inclusão? A partir desse debate, María Rigat-Pflaum (2008) também critica um suposto caráter integracionista das estratégias de transversalização de gênero, que levam "a enfatizar os aspectos mais formais do enfoque e descartar uma implementação menos declarativa e mais concreta, mais centrada na 'fixação de agendas' (agendasetting)", tornando o gender mainstreaming "uma estratégia de igualdade similar a qualquer outra, o que implica ignorar (e desperdiçar) seu potencial transformador" (RIGAT-PFLAUM, 2008, p. 48).

As teses, dissertações e artigos publicados no Brasil parecem ter menos preocupação, no geral, com o problema da operacionalização da transversalidade em âmbitos federais. Em sua maioria, as pesquisadoras se preocupam com uma política pública específica, deixando a discussão sobre a operacionalização da transversalidade de gênero como pano de fundo. Ainda assim, há questões levantadas pelas pesquisadoras brasileiras - e questões que inserem a transversalidade no contexto da América Latina.

Cecília Sardenberg (2010), como já indicamos anteriomente, argumenta que não há consenso em torno da tradução de gender mainstreaming, o que poderia ser um problema para seu uso nas análises empreendidas. A autora, assim como Prá (2010), sinaliza que há uma diferença no sentido atribuído a esses termos, uma diferença que implica inclusive uma disputa nos modos de implementação da política. Em uma tradução mais direta, mainstreaming implicaria agregar uma determinada vertente em todas as políticas públicas, neste caso seria incorporar gênero em todas as políticas. Mudanças conceituais, diz Prá (2010), "[...] adquirem mais força e clareza a partir do evento [Beijing, 1995], tornando-se perceptíveis, dado o processo de transformação nos conteúdos das políticas públicas estimulados pelo aporte de gênero." A autora afirma ainda que, a partir disto, "[...] se intensificam os esforços por superar 0 
caráter marginal de políticas tidas, de início, como responsabilidade exclusiva dos mecanismos de defesa dos direitos da mulher", buscando-se, hoje, "[...] integrar agendas políticas nacionais, com uma visão de processo de médio e longo prazo e de estratégias e ações voltadas à equiparação entre os sexos" (PRÁ, 2010, p. 26-27). A esta discussão que investe em uma distinção conceitual entre transversalidade e transversalização articula-se, então, também outra diferença conceitual e operativa importante que já destacamos, qual seja, a que pretende fazer frente ao uso indistinto dos termos equidade e igualdade de gênero tanto nas políticas quanto nas publicações.

Por conta disso, concordamos com Papa (2012), que considera que a transversalização tem sido indicada no Brasil sem um lastro conceitual mais consistente, uma vez que "se afirma que as perspectivas de direitos específicos das mulheres [...] serão tratados de forma transversal, sem, contudo, se explicar quem fica responsável por desenvolver as ações, com que prioridade política e orçamentária" (PAPA, 2012, p. 139). Ou seja, o princípio tem sido incorporado nos textos das políticas, embora encontre dificuldades de efetivamente ser operacionalizado de um modo mais amplo.

Tatiana Silva (2011) identifica uma característica "departamentalizada" com a qual a estratégia da trasnverzalização de gênero opera no Brasil. A operação e institucionalização desse instrumento teria ficado restrita aos trabalhos da Secretaria de Políticas para as Mulheres (SPM) e, portanto, inscrita em seus departamentos.

\section{CONSIDERAÇÕES}

Destacamos, então, alguns aspectos sistematizados com o exame e a análise desse material. Começamos destacando a polifonia discursiva posta em funcionamento nos textos localizados, ou seja, os diferentes modos de definir/teorizar e analisar um mesmo instrumento teórico e operacional como esse da transversalidade. Nessa polifonia chamamos atenção para o uso pouco expressivo da expressão "transversalidade de gênero" como indexador de trabalhos acadêmicos. Tal situação pode afetar a busca por tais estudos, o que vivenciamos em nosso trabalho. A produção de estudos em torno dessa problemática tambem não parece ser muito numerosa, não só no Brasil.

Um outro viés, indicado pelos trabalhos analisados, diz respeito ao não reconhecimento e/ou explicitação das inscrições teóricas - e portanto também estratégicas e políticas - contidas nos diferentes usos das noções de transversalidade/transversalização, assim como do próprio conceito de gênero nos termos propostos, por exemplo, nos textos de Prá(2010) eSardenberg(2010), antes citados. Nessesentido, algumas pesquisas sugerem, por exemplo, que interesses políticos e de manutenção cultural podem estar impedindo que esta estratégia seja implementada, dificultando, desta forma, que estas relações 
assimétricas de poder sejam colocadas em discussão. Para além disso, o caráter polissêmico em torno dos termos transversalidade/transversalização, visível nas diferentesformas defalarsobreeles, dificultaque se construa um consenso mínimo, necessário quando se trata de pactuar a elaboração e implementação de políticas públicas que incorporem esse princípio; sobretudo quando se considera que uma política pública deve fomentar essas estratégias transversais, em nível de Estado, direcionando-as para grandes grupos da população. Assim, a revisão feita indica que, justamente por esse caráter polissêmico e multifacetado, e por seu viés predominantemente cis-heteronormativo, o termo transversalidade de gênero está marcado por disputas de poder e significação.

Cabe também recuperar, aqui, a crítica de TatianaSilva(2011)à departamentalização da transversalidade de gênero no Brasil, uma vez que ela estaria sob responsabilidade da Secretaria de Políticas para as Mulheres (SPM). Esse viés departamentalizado teria contribuido para reforçar a ideia de que "mulheres" e "gênero" seriam sinônimos na esfera das políticas públicas. Muitos dos trabalhos analisados sugerem que uma abordagem de gênero se traduz como uma abordagem em mulheres e, em parte, isso é decorrência do baixo investimento na discussão conceitual, não só dos termos transversalidade e transversalização, mas também de sua articulação aos conceitos de gênero, equidade e igualdade, muito enfatizada, mas não discutida, nesses estudos e políticas.

Além disso, levando em conta essa ação departamentalizada, questionamo-nos sobre o futuro dessa estratégia política após a reforma ministerial de 2015, na qual a ex-presidenta Dilma Rousseff vinculou essa Secretária e a Secretaria de Políticas de Promoção da Igualdade Racial (SEPPIR) ao Ministério dos Direitos Humanos, tirando delas seu status de ministério, um desmonte ampliado com o Governo Temer, a partir de 2016, e radicalizado com o governo de Jair Bolsonaro, a partir deste janeiro de 2018.

Os estudos apontam que não tem sido possivel implementar a transversalização em suas múltiplas dimensões (práticaseestratégicas), sejaporfalta derecursos, capacitação ou gestão. Isso incluia dificuldade em unificar as demandas encabeçadas pelos movimentos feministas, de mulheres, transfeministas e LGBTTIQ+ em sua multiplicidade, e esse desafio parece ser bem mais amplo do que a mera incorporação de um modo de dizer mais inclusivo. Envolve o desenvolvimento de construtos conceituais explicitamente assumidos e pactuados e ações concretas balisadas por eles, a fim de trazer para dentro das políticas, de modo igualitário, sujeitos que historicamente têm ficado fora delas.

Por fim, a crítica que Carin Klein et al. (KLEIN et al., 2013, p. 910) fazem ao Estado neoliberal na gestão do gender mainstreaming ganham uma perigosa atualidade. Para elas, "em vez de prover e garantir serviços públicos amplos, gratuitos e de qualidade", o Estado neoliberal "atua por intermédio de campanhas, programas e políticas públicas residuais e direcionadas, sobretudo, às populações mais pobres, no sentido de 'ajudar as pessoas a se ajudarem [...]'" (KLEIN et al., 2013, p. 910). Ademais, por caracterizar- 
se também pela diminuição da interferência do Estado na política (UBERTI, 2012), entendemos que a radicalização de formas de governar neoliberais também ameaça seriamente a proposição de políticas públicas que objetivem promover equidade para produzir igualdade de gênero, de sexualidade de raçã/ etnia e de outras iniquidades sociais.

Acreditamos, entretanto, que apesar dos problemas aqui indicados a transversalização de gênero tem grande potencial para contribuir para a formulação de políticas públicas focadas na diminuição de desigualdades de gênero em todos os niveis e contextos, e isso reverbera também nos trabalhos aqui analisados. Uma potência cuja materialização parece ter ficado ameaçada e mais distante nestes tempos que vivemos, mas que persevera e insiste...

\section{REFERÊNCIAS}

ANDRADE, Sandra dos S.; BARZOTTO, Carlos E. Transversalidade de gênero: um conceito para analisar políticas públicas. In: 6 SBECE $/ 3^{\circ} \mathrm{SIECE}, 2015$. Anais... 2015.

ANDRADE, Priscila M. A Economia Solidária é Feminina? Análise da Política Nacional de Economia Solidária sob a Perspectiva de Gênero. Dissertação (mestrado e Serviço Social) - Instituto de Ciências Humanas, Universidade de Brasília, Brasília, 2007. Disponível em: <http://repositorio.unb.br/handle/10482/3505?mode=full>. Acesso em: 20 fev. 2017.

\section{BANDEIRA, Lourdes. Fortalecimento da Secretaria Especial de Políticas para as Mulheres: avançar na} transversalidade da perspectiva de Gênero nas Políticas Públicas. Brasília: SPM, Cepal, 2005. Disponível em: <http://portal.mte.gov.br/data/files/FF8080812BAFFE3B012BCB0932095E3A/integra_publ_lourdes_bandeira. pdf>. Acesso em: 20 abr. 2016.

. 0 que não estamos conseguindo alterar na questão da violência contra a mulher? Articulando - Encarte do Jornal CFêmea, [S.I.], n. 129, out. 2003.

BERTOLLO, Sandra H. SCHWENGBER, M. Simone V. III Plano Nacional de Políticas para as mulheres: percurso de uma pré-política de esporte e lazer. Revista Movimento da UFRGS, v. 23, n. 2, abr./jun. 2, 2017.

BRASIL. Ministério do Planejamento. Plano Plurianual 2004-2007. Brasilia: [s/n], 2003. Disponível em: <http://www. sigplan.gov.br/arquivos/portalppa/41_\%28menspresanexo\%29.pdf>. Acesso em: 02 fev. 2016.

. Ministério do Planejamento. Plano Plurianual 2008-2011. Brasília: [s/n], 2007. 
. Ministério da Economia. Plano Plurianual 2012-2015. Brasília: [s/n], 2011. Disponível em: <http://www. planejamento.gov.br/assuntos/planeja/plano-plurianual/publicacoes/2012-2015>. Acesso em: 08 fev. 2019.

_. - _ _. Ministério do Planejamento. Plano Plurianual 2016-2019. Brasília: [s/n], 2015. Disponível em: <http:// www.planejamento.gov.br/secretarias/upload/arquivo/spi-1/ppa-2016-2019/ppa-2016-2019-ascom-3.pdf>. Acesso em: 19 set. 2016.

. Secretaria Especial de Políticas Públicas para as Mulheres. I Plano Nacional de Políticas para as Mulheres. Brasília: [s/n], 2004. <http://bvsms.saude.gov.br/bvs/publicacoes/PNPM.pdf>. Acesso em: 19 set. 2016.

Secretaria Especial de Políticas Públicas para as Mulheres. II Plano Nacional de Políticas para as Mulheres. Brasília: [s/n], 2008. Disponível em: <http://portal.mec.gov.br/dmdocuments/planonacional_politicamulheres.pdf>. Acesso em: 23 abr. 2016.

. Secretaria Nacional de Políticas Públicas para as Mulheres. III Plano Nacional de Políticas para as Mulheres. Brasília: [s/n], 2013. Disponível em: <http://www.spm.gov.br/assuntos/pnpm/publicacoes/pnpm2013-2015-em-22ago13.pdf>. Acesso em: 05 abr. 2017.

Secretaria de Políticas Públicas para as Mulheres. Orientações Estratégicas para Institucionalização da Temática de Gênero nos Órgãos Governamentais. Brasilia: [s/n], 2011. Disponível em: <http://www.spm.gov.br/assuntos/pnpm/publicacoes/orientacoes_estrategicas>. Acesso em 12 fev. 2017.

Presidência da República. Secretaria Especial de Políticas para as Mulheres. I Conferência Nacional de Políticas para as Mulheres. Brasília [s/n], 2004. Disponível em: <http://www.observatoriodegenero.gov.br/menu/ publicacoes/outros-artigos-e publicacoes/anais-da-i-conferencia-nacional-de-politicas-para-as-mulheres/ view>. Acesso em: 08 fev. 2019. ${ }^{9}$

Presidência da República. Secretaria Especial de Políticas para as Mulheres. II Conferência Nacional de Políticas para as Mulheres. Brasília [s/n], 2007. Disponível em: <http://www.observatoriodegenero.gov.br/menu/

\footnotetext{
${ }^{9}$ Por conta da reforma ministerial de 2019, o site que anteriormente continha os documentos da então Secretaria de Políticas Para as Mulheres foi retirado da rede e substituído pelo site do Ministério da Mulher, da Família e dos Direitos Humanos. Nesse processo, alguns documentos (como as Conferências Nacionais de Políticas para as Mulheres) deixaram de ficar disponíveis. Por conta disso, alguns dos links citados não provêm de plataformas oficiais da Presidência da República, como o eram no momento de realização da pesquisa. Além disso, não foi possível achar o documento de uma das Conferências em específico, que ficou sem o link para acesso.
} 
publicacoes/outros-artigos-e-publicacoes/ii-conferencia-nacional-de-politicas-para-as-mulheres-regimento-e-plano-nacional-de-politicas-para-as-mulheres-versao-compacta/view>. Acesso em: 08 fev. 2019.

_._-___. Presidência da República. Secretaria Nacional de Políticas para as Mulheres. III Conferência Nacional de Políticas para as Mulheres. Brasília [s/n], 2011.

KLEIN, Carin. MEYER, Dagmar E. E.; BORGES, Zumira N. Políticas de Inclusão social no Brasil contemporâneo e educação da maternidade. Cadernos de Pesquisa (Fundação Carlos Chagas. Impresso), v. 43, p. 906-923, 2013.

LABRECQUE, Marie France. Transversalização da perspectiva de gênero ou instrumentalização das mulheres?.

Rev. Estud. Fem., Florianópolis, v. 18, n. 3, dez. 2010.

LAVINAS, Lena. 21ST CENTURY WELFARE. New left review, n. 84, nov./dec. 2013.

LOMBARDO, Manuela. Integrating or Setting the Agenda? Gender Mainstreaming in the European Constitution-Making Process. Social Politics, Oxford, v. 12, p. 412-432, 2005. Disponivel em: <https://academic.oup. com/ sp/article-abstract/12/3/412/1679268/Integrating-or-Setting-the-Agenda-Gender>. Acesso em: 20 fev. 2017.

LOMBARDO, Manuela; MEIER, Petra. Incorporating a Feminist Reading? European Journal of Women's Studies, London, v. 13, n. 2, p. 151-166, 2006. Disponível em: <http://maint.journals.sagepub.com/>. Acesso em: 20 fev. 2017.

MAROTE, Ana S. F.; PINTO, Carla A.; VIEIRA, Marlene R.; BARBIÉRI-FIGUEIREDO, Maria C. A.; PEDROSA, Pedro M. N. Crianças como cuidadoras: revisão integrativa. Rev. Latino-Am. Enfermagem, Ribeirão Preto, v. 20, n. 6, p. 1-10, 2012. Disponivel em: <http://www.scielo.br/scielo.php?pid=S010411692012000600023\&script=sci_arttext\&tlng=pt $>$. Acesso em: 20 fev. 2017.

MELO, Marisol Vieira. Três décadas de pesquisa em Educação Matemática: um estudo histórico a partir de teses e dissertações. Dissertação (mestrado em Educação) - Faculdade de Educação, Universidade Estadual de Campinas, 2006.

MEYER, Dagmar e Cols. A educação da família como estratégia governamental de inclusão social: um estudo situado na interface dos Estudos Culturais, de Gênero e de Vulnerabilidade. Porto Alegre: Faculdade de Educação, Universidade Federal do Rio Grande do Sul, 2008. (Relatório de Pesquisa)

MOSER, Caroline; MOSER, Annalise. Gender Mainstreaming since Beijing: a Review of Success and Limitations in International Institutions. Gender \& Development, v. 13, p. 11-22, 2005. Disponivel em: <http://www.tandfonline. 
com/doi/abs/10.1080/13552070512331332283>. Acesso em: 20 fev. 2017.

NEVES, Jonas Anderson das; ANTONELLI, Carolina de Santi; DA SILVA, Mariana Girotto Carvalho; CAPELLINI, Vera Lúcia Messias Fialho. Escolarização formal e dimensões curriculares para alunos com autismo: o estado da arte da produção acadêmica brasileira. Educação em Revista, Belo Horizonte, v. 30, n. 2, p. 43-70, 2014.

PAPA, Fernanda de C. Transversalidade e políticas públicas para mulheres no Brasil - percursos de uma pré-política. Dissertação (mestrado em Administração Pública e Governo) - Escola de Administração de Empresas de São Paulo, Fundação Getúlio Vargas, São Paulo, 2012. Disponível em: <http://bibliotecadigital.fgv.br/dspace/handle/10438/9850>. Acesso em: 20 fev. 2017.

PILLÃO, Delma. A pesquisa no âmbito das relações didáticas entre matemática e música: estado da arte. Dissertação (mestrado em Educação) - Faculdade de Educação, Universidade de São Paulo, São Paulo, 2009.

PRÁ, Jussara. Políticas para mulheres - transversalizar é preciso. In: ALVES, Ivia; SCHEFLER, Maria de Lourdes; VAZQUEZ, Petilda Serva; AQUINO, Silvia de (Org.). Travessias de gênero na perspectiva feminista. Salvador: EDUFBA/NEIM, 2010, p. 13-36.

REINACH, Sofia. Gestão Transversal das políticas públicas no âmbito federal brasileiro: uma leitura inicial. Dissertação (mestrado em Administração Pública e Governo) - Escola de Administração de Empresas de São Paulo, Fundação Getúlio Vargas, São Paulo, 2013. Disponível em: <http://bibliotecadigital.fgv.br/dspace/handle/10438/10667>. Acesso em: 20 fev. 2017.

RIGAT-PFLAUM, María. Gender Mainstreaming: un enfoque para la igualdad de género. Nueva Sociedad, Buenos Aires, n. 218, p. 40-56, 2008. Disponível em: <http://www.inmujeres.gub.uy/innovaportal/file/21671/1/35_maistreaming.pdf>. Acesso em: 20 fev. 2017.

ROMANOWSKI, Joana Paulin; ENS, Romilda Teodora. As pesquisas denominadas do tipo "estado da arte" em educação. Diálogo Educ., Curitiba, v. 6, n. 19, p. 37-50, 2006.

ROMANOWSKI, Joana Paulin; VOSGERAU, Dilmeire Sant'Anna R. Estudos de revisão: implicações conceituais e metodológicas. Rev. Diálogo Educ., Curitiba, v. 14, n. 41, p. 165-189, 2014.

RUIZ, Juana M. G. El derecho internacional de los derechos humanos y su apertura al principio del Gender Mainstreaming: el caso español. Revista del Instituto de Ciencias Juridicas de Puebla, Puebla, ano V, n. 28, p. 243-277, 2011. Disponível em: <http://www.scielo.org.mx/scielo.php?script=sci_arttext\&pid=S187021472011000200012>. Acesso em: 20 fev. 2017. 
SARDENBERG, Cecília M. B. Da transversalidade à transversalização de gênero: aportes conceituais e práticopolíticos. In: ALVES, Ivia; SCHEFLER, Maria de Lourdes; VAZQUEZ, Petilda Serva; AQUINO, Silvia de (Org.). Travessias de gênero na perspectiva feminista. Salvador: EDUFBA/NEIM, 2010, p. 37-73.

SERRA, Albert. La géstion transversal. Expectativas y resultados. Revista del CLAD Reforma y Democracia, Caracas, n. 32, p. 1-17, 2005. Disponível em: <http://siare.clad.org/revistas/0049633.pdf>. Acesso em: 20 fev. 2017.

SILVA, Tatiana Dias. Gestão da Transversalidade em Políticas Públicas. In: ENCONTRO DO ANPAD, 35., Rio de Janeiro, 2011. Anais... [s/l]: [s/n], 2011. Disponivel em: <http://www.anpad.org.br/admin/pdf/APB2041.pdf>. Acesso em: 09 fev. 2017.

STRASBOURG. Gender Mainstreaming - Conceptual framework, methodology and presentation of good practices. Strasbourg: [s/n], 1998. Disponivel em: <http://www.unhcr.org/protection/women/3c160b06a/gender-mainstreaming-conceptual-framework-methodology-presentation-good.html>. Acesso em: 12 fev. 2017.

TREINTA, Fernanda Tavares; FILHO, José Rodrigues Farias; SANT'ANNA, Annibal Parracho; RABELO, Lúcia Mathias. Metodologia de pesquisa bibliográfica com a utilização de método multicritério de apoio à decisão. Revista Production, v. 24, n. 3, p. 508-520, 2014.

TRINDADE, Fernanda de Magalhães; SCHWENGBER, Maria Simone Vione. III Plano Nacional de Políticas para as Mulheres: a transversalidade de gênero e a educação. Educação (Santa Maria. Online). Epub: 04-abr.-2017 Disponivel em: <http://www.ufsm.br/revistaeducacao >. Acesso em:08 fev. 2019.

UBERTI, Luciane. Currículo e Poder: para além das forças do Estado - ainda há o que dizer? Anais da 35a Reunião anual da ANPED, p. 1-16, 2012.

VÁSQUEZ-GARCÍA, Verónica. Gender Mainstreaming y agua. El Programa Nacional Hídrico. Convergencia, Revista de Ciencias Sociales, Cidade do México, n. 56, p. 111-132, 2011. Disponível em: <http://www.redalyc.org/articulo. oa?id=10516855005> Acesso em: 20 fev. 2017.

WALBY, Sylvia. Gender Mainstreaming: Productive Tensions in Theory and Practice. Social Politics, Oxford, v. 12, p. 321-343, 2005. Disponivel em: <http://www.research.lancs.ac.uk/portal/en/publications/gender-mainstreaming-productive-tensions-in-theory-and-practice(9b151aab-2c6c-4d28-a447-81a5609abe03)/export.html>. Acesso em: 20 fev. 2017. 